Sergio Zañartu, s.j.

Profesor de la Facultad de Teología

Pontificia Universidad Católica de Chile

\title{
Recuerdos de la Facultad y reflexiones*
}

Señor Decano, queridos profesores y alumnos:

Agradezco muy sentidamente la distinción que hoy me otorga la Universidad al nombrarme profesor emérito de esta Facultad. Para mí, esto significa mucho. Es la coronación de un servicio eclesial, al que he consagrado mi vida sacerdotal. Comencé el año 1967, siendo Rector Monseñor Silva Santiago, en el originario y hermoso edificio de la Facultad. Jorge Medina era decano y la Facultad brillaba con sus peritos conciliares, como Egidio Viganó y Juan Ochagavía (1), y con sus nuevas adquisiciones como Beltrán Villegas. El encargado de la Biblioteca era Antonio Moreno (2). Todos los nombrados fueron decanos de la Facultad, salvo Egidio Viganó, quien elegido por la unanimidad de los votos no aceptó, al ser nombrado Provincial de los Salesianos. Eran tiempos de unidad: los teologados de los Sagrados Corazones y de los Salesianos, posteriormente, convergían a la Facultad, donde, desde su fundación, habían estudiado los seminaristas diocesanos. Los jesuitas se trasladaban desde Argentina.

Mi primer curso iba a versar sobre Bautismo y Confirmación, pero me fue cambiado por un seminario para los futuros licenciados (3) en Teología sobre Ignacio de Antioquía, tema de la tesis doctoral que hacía. Entre los alumnos se contaba el actual profesor Cristián Johansson. Este inicio se tradujo en que hasta 1982 fui el profesor de Patrología e Historia de la Iglesia Antigua. Se me llamaba para asignarme las clases que la programación necesitaba, pero nunca se me preguntó en qué deseaba especializarme. Cuando llegué a ser decano (1980), intenté que esto cambiara. Después pedí que se me asignara una materia dogmática. Así comencé a enseñar Cristología (4) y Trinidad, primero en el A y después en el B, hasta el

* Palabras de agradecimiento del profesor Sergio Zañartu, s.j., con ocasión de recibir el título de profesor emérito. 15 de octubre de 2002

(1) Llevado por el Cardenal Silva. J. Medina, igualmente, era perito.

(2) Cuando este cesó, por 1968, me ofrecieron a mí el cargo. Lo decliné y propuse a Fernando Astorquiza. Pero terminé cediendo, ya que desde 1996 he sido el coordinador académico de ella. Acabo de renunciar al no estar conforme con el Proyecto de SIBUC respecto al grado de apertura que tendría la futura Biblioteca de Teología, cuando se instale en el campus San Joaquín.

(3) Al poco tiempo, por recomendación de la Sagrada Congregación, se comenzó a exigir una tesina para la licencia.

(4) La primera vez (1984) me dieron una cátedra de Cristología en el A, paralela con el profesor Maximino Arias. 
presente. Mis 36 años de trabajo en la Facultad han sido de docencia, sobresaliendo en ella los dos decanatos y la actual dirección del Postgrado. Creo conocer un poco la Facultad, de la que ahora me despido como profesor de planta. Y, por eso, en esta despedida quisiera reflexionar sobre algunos pocos puntos de su historia, en el lapso que me ha tocado compartirla, y decir algo sobre su desafío futuro. Estas reflexiones son personales, parciales e incompletas. Pero pueden inspirar a otros para construir una visión mejor y más equilibrada. Desde ya pido disculpas por lo que haya de inexacto en este testimonio. Pido disculpas sobre todo a los que conmigo han compartido esta aventura y se están retirando.

\section{1) TEOLOGÍA LATINOAMERICANA}

Nos ha tocado vivir el 'boom' de la teología de la liberación. ¡Bendito movimiento que nos ha dado voz en el concierto mundial! Fue una voz profética de amor al pobre contra la injusticia. La voz de Jesús predicando el reino remeció nuestras vidas y despertó una gran esperanza de liberación. Pero la liberación no se ha producido. Por otra parte, cayeron las categorías marxistas que apoyaban el análisis de la realidad en esa teología. En el Cristo crucificado encontraron sentido muchos crucificados de la historia en nuestro subcontinente. El fenómeno de la Teología de la Liberación produjo en algunos centros de estudios una especie de guerra de trincheras para defenderse o para atacar. Lamentablemente las luchas de trincheras, en que siempre se insiste en las líneas gruesas y de lo mismo, suelen ser acompañadas de una cierta cuota de esterilidad. Probablemente la mayoría del profesorado de nuestra Facultad se mantuvo abierto o simpatizó con la teología de la liberación (algunos se opusieron). Pero, gracias a Dios, no se produjo atrincheramiento y seguimos pensando con cierta independencia (5). En mi primer decanato (1980-1982), la Facultad asistió masivamente a una conferencia de Leonardo Boff programada para nosotros en la sede de CONFERRE (6); y en mi segundo decanato (1992-1994) recibíamos oficialmente a Gustavo Gutiérrez. La Facultad también ha programado cursos sobre la Teología de la Liberación.

En esos tiempos se desarrolló asimismo una revalorización de la religiosidad popular. La Facultad se embarcó en esta línea y organizó seminarios, encuentros, conferencias e hizo diversas publicaciones (7). Símbolo de eso es un rehue, que actualmente no termina de encontrar su espacio adecuado en los pasillos de la Facultad. Recuerdo la ida de algunos profesores y alumnos a la fiesta de la Tirana. Justamente el seminario de profesores de este año está consagrado a: Religiosidad popular y espacio sagrado. Sería nuestro cuarto seminario de religiosidad popular (8). Un gran

(5) La genial creación del Comité pro Paz, que desembocó en la Vicaría de la Solidaridad, a mi entender, no se debió a la Teología de la Liberación sino al catolicismo social avanzado, que vivía nuestra Iglesia.

(6) Se nos había vetado recibirlo en nuestra propia sede.

(7) Se puede destacar la tesis doctoral del profesor Cristián Johansson: Religiosidad popular entre Medellín y Puebla: antecedentes y desarrollo, Anales XLI.

(8) Siempre con algún invitado extranjero. 
impulso a lo latinoamericano lo dio Maximino Arias con la creación del Seladoc. Antonio Bentué lo continuó. En tiempo de Sergio Silva se constituyó un thesaurus para estandarizar y mejorar la catalogación de innumerables artículos de revistas latinoamericas. Esta utilísima base de datos se puede consultar en nuestra Biblioteca, que esperamos cuente, en su edificio futuro, con una sala latinoamericana (9). El Seladoc, entre otras cosas, publicó ocho volúmenes de Panoramas de la teología latinoamericana (10) y otros siete sobre religiosidad popular, titulados "La fe de un pueblo" (11).

Otra línea de teología latinoamericana es la de investigar la propia historia, beber en el propio pozo (12). La Facultad en Anales ha hecho una contribución notable en este aspecto. Julio Jiménez, entre sus especialidades, en este período dedicó parte de su tiempo a temas históricos (13). Gabriel Guarda (14) y Fernando Retamal (15) siguieron también este camino. Mauro Mathei nos deleitó con Cartas e informes de los misioneros jesuitas extranjeros en Hispanoamérica (16). Juan Noemi (17) dio un nuevo impulso con la serie El pensamiento teológico en Chile. Contribución a su estudio (18); dirigió además la investigación sobre los 40 años de Teología y Vida (19).

(9) A la bibliografía latinoamericana contribuye A. Bentué con L'Església que és a Amèrica. Literatura teològica Llatinoamericana, 1968-1992 (Facultat de Teologia de Catalunya, 1993), y sus tres suplementos que alcanzan hasta el año 2000.

(10) En la editorial Sígueme de Salamanca. Comenzaron con dos volúmenes de Selecciones de teología de la liberación. Después trataron de: religiosidad popular, Iglesia y seguridad nacional, Puebla, Cristología, educación, la mujer.

(11) M. Jordá, La sabiduría de un pueblo, Santiago 1975, ed. Mundo; Religiosidad popular y fe en A. L. Ponencias y documento del Encuentro Latinoamericano de Religiosidad Popular, Santiago 1975, ed. Mundo; M. Jordá, El catecismo criollo, Santiago 1976, ed. Salesianos; J. Van Kessel, El desierto canta a María (2 vol.), Santiago 1976, ed. Mundo; Historia y misión. Ponencias, aportes y experiencias del Segundo Encuentro de Religiosidad Popular, Santiago 1977, ed. Mundo; M. Alonqueo, Instituciones religiosas del pueblo mapuche, Santiago 1979, ed. U.C.

(12) Me restringiré solo a lo publicado en Anales.

(13) El Abate Molina. Humanista clásico y sabio cristiano..., Anales XXIV, 2.; Juan Ignacio Molina, talquino de cuna y de alma..., Anales XXVIII, 2. Y entre sus discípulos: José Arteaga, Gobierno como electo y juramento civil del arzobispo $R$. V. Valdivieso. 1845-1848, Anales XXVII, I; Maximiliano Salinas, El laicado católico de la Sociedad Chilena de Agricultura y Beneficencia 1838-1849..., Anales XXIX, 1; Charles Hallet, "El congregante perfecto" del Padre Ignacio García Gómez, S.J., Anales XXXII, 1.

(14) La implatación del monacato en Hispanoamérica. Siglos XV-XIX, Anales XXIV, 1; Centros de evangelización en Chile, Anales XXXV. El profesor G. Guarda recibió posteriormente el premio nacional de historia.

(15) Escritos menores de la misión Muzi, Anales XXXVII, 1; Chilensia Pontificia. Monumenta Ecclesiae Chilensia, Anales (fuera de serie), 5 volúmenes.

(16) Anales XX, 4; XXI, 3; XXIII, 3; XLVIII, 2; LII

(17) Este profesor también ha insistido siempre en el respeto a la razón moderna.

(18) Anales XXVII, 2; XXXI, 1 (dirigido por J. Arteaga); XXXVIII, 1 (Marciano Barrios); XL, 2 (Marciano Barrios); XLIV, 2 (Freddy Parra); XLVI, 2 (Marciano Barrios). Marciano Barrios también publicó: La Facultad de Teología de la Pontificia Universidad Católica de Chile. Sesenta años de historia al servicio de Chile y de su Iglesia (1935-1995), Santiago 1995. Igualmente editó y colaboró en los 4 volúmenes del Episcopologio chileno 1561-1815, dirigido por el Cardenal Oviedo. A los estudios históricos latinoamericanos de Anales habría que añadir: Walter Repges, Hacia una pastoral del compromiso temporal. La Iglesia entre Río de Janeiro (1955) y Medellín (1968), XXIII, 1; Fernando Aliaga, La misión en la isla Dawson (1889-1911), XXXII, 2; Fernando Aliaga, Relaciones a la Santa Sede enviadas por los obispos del Chile colonial, XXV, 1: L. E. Silva, La elección del Arzobispo Crescente Errázuriz Valdivieso, XL, 1.

(19) Cf. Teología y Vida, XLI, 3s, 2000. 
Mientras se daba el 'boom' de la Teología de la Liberación y después, muchos centros de estudios de América Latina continuaron con su callada, paciente y prolija labor de transmisión viva de la revelación a futuros ministros de Iglesia y teólogos, lo que se refleja en sus publicaciones. Se pensó que tomar conciencia de esto podría eventualmente ser base como para una segunda ola de teología latinoamericana. Así nuestra Facultad, especialmente por iniciativa de Sergio Silva, convocó a un "Encuentro de Facultades Latinoamericanas que editan revistas teológicas" (20). Posteriormente se tuvo otro encuentro en Buenos Aires (21). En 1990 nace la Sociedad Chilena de Teología, impulsada en buena parte por profesores de nuestra Facultad que deseaban encontrarse como teólogos en un ámbito diferente al de nuestros Institutos. Esta sociedad, hasta la fecha, ha realizado fructíferos encuentros anuales, que han fomentado el desarrollo de la teología en Chile (22). Con posterioridad, las Sociedades de Teología del Cono Sur se asocian y ya han realizado tres encuentros internacionales, el último de los cuales fue en nuestro país en 2001.

El grupo de patrólogos de nuestra Facultad (23) ha respondido al desafío de la teología latinoamericana con un acercamiento peculiar. Opinan que para una teología más genuina de nuestras Iglesias (por tanto más independiente de las circunstancias de Europa) que sea profunda, es básico un buen dominio de la revelación y su tradición, en la que tanto se destacan los Padres de la Iglesia. Pretenden hacer teología leyendo a los Padres desde nuestra realidad. Responden así a la especial necesidad que experimentan las épocas de cambio de volver a reinterpretar las fuentes. En este camino la Facultad de Teología, junto con la Facultad de Filosofía de nuestra Universidad, ya ha realizado seis Seminarios de Estudios Patrísticos, a lo largo de 25 años, con participación de patrólogos argentinos y algunos europeos (24). Actualmente los seis profesores con doctorado en patrología organizaron un Magíster con mención en teología patrística (25), de reciente aprobación, que cons-

(20) Cf. Teología y Vida XXXVI, 3, 1995.

(21) Véase crónica de S. Silva, Teología y Vida XXXIX (1998) 417-422.

(22) Cf. S. Zañartu, Algunos recuerdos y reflexiones sobre la Sociedad Chilena de Teología al cumplirse 10 años de su existencia, en Sociedad Chilena de Teología, El Padre, pp. 197-214, Talca 2000. Pero la influencia más notable de nuestra Facultad en los otros institutos de nuestro país, se realiza a través de la actual afiliación del Seminario Pontificio de Santiago, y del de San José de la Mariquina, y a través de muchos titulados en nuestra Facultad, que trabajan en diversos institutos. Respecto a la influencia en la Iglesia chilena y en el país, basta con hojear, en las cuentas anuales de los decanos, las innumerables actividades de los profesores. Estas actividades también se extienden a la participación en variados congresos internacionales, etc. Así nuestra Facultad ha estado presente en la Comisión Teológica Internacional en 4 de los 6 quinquenios, y en la Comisión para la Reforma del Derecho Canónico, en la Comisión Bíblica. Por otro lado, dos ex profesores de nuestra Facultad han llegado a ser cardenales (Mons. Oviedo y Mons. Medina) y varios han sido consagrados como obispos.

(23) Considero una bendición de Dios que seamos seis los profesores de la planta con tesis doctoral en Padres de la Iglesia. Así se realza lo imprescindible de la Tradición para el quehacer teológico. Por otra parte, sería también importante en la formación de futuros profesores, que estos tengan una seria confrontación con la filosofía, incluida la moderna. Es de esperar que un mayor desarrollo de la Teología Fundamental en la Facultad incida en un mejor diálogo con la filosofía.

(24) Puede verse la crónica de S. Zañartu, El estudio de los Padres de la Iglesia en la Facultad de Teología desde 1967 hasta el presente. Impresiones, Teología y Vida XL (1999) 439-445. Los trabajos del último (VI) Seminario de Estudios Patrísticos los podemos consultar en Teología y Vida XLII, núm. 2s, del año 2002; los del anterior (V), en Teología y Vida XXXIX, 3s, del año 1998. 
tituye un desafío de futuro de cara a América Latina. Continuando con los postgrados, creo que en ellos se juega parte del futuro de la teología latinoamericana. Sería conveniente que las distintas Facultades potenciaran diferentes menciones, especializándose un poco según sus capacidades, de manera de tener en América Latina estudios de Magíster de calidad. Así nuestros mejores estudiantes no tendrían que acudir a Europa en esta etapa. Y no es lo mismo, mientras se elabora una tesina, estar viviendo la problemática de la teología europea que estar viviendo los acuciantes problemas pastorales y político-sociales de nuestro subcontinente. Y desde una mejor teología latinoamericana contribuiremos más a la Iglesia universal.

\section{2) LOS CURRÍCULOS DE NUESTRA FACULTAD}

Muy decisivo para esta Facultad ha resultado la creación en 1968 de un currículo aparte para el grado canónico de bachiller, el B, siendo los grados canónicos la máxima preocupación académica de la Facultad (art. 111 de los Estatutos) (26). El currículo A, por otro lado, "programa de Ciencias Religiosas se ordena, como el de Sagrada Teología (el currículo B), a proporcionar una comprensión complexiva y unitaria de la Fe Católica, pero está destinado directamente a la capacitación teológica del personal consagrado a la misión pastoral de la Iglesia, y así difiere de aquel por sus objetivos, exigencias, métodos y currículo" (art. 120). Así se ofrecían dos opciones a las dispares expectativas de los alumnos. Esto hizo que, mientras en muchas partes de la Iglesia se notará una decadencia de los estudios teológicos en la época postconciliar, en nuestra Facultad (en el B) el nivel o se mantuvo o mejoró. Para el B, además de los rudimentos de griego y latín, se exigía el uso de dos lenguas extranjeras modernas (27). En el B, que directamente pretende formar teólogos, entró con fuerza la historia del dogma (28). Se esperaba que la mayoría de los alumnos optara por el A. La exigencia de lenguas modernas decayó, cuando su control pasó al curso de inglés de la Universidad, que por lo demás también se exigió para el A (29). Esto, junto con profesores que no distinguían bien las diversas orientaciones de los currículos y que exigían, no cosas diferentes, sino

(25) Hasta el presente solo se había dado el título de licenciado con mención en teología dogmática. Recientemente se ha abierto también una mención en teología fundamental, de gran importancia en el diálogo con el mundo que nos rodea. El hecho de que haya actualmente 6 patrólogos, casi todos haciendo ramos dogmáticos, contribuye a dar peso a la teología de la Facultad.

(26) Esto puede leerse al revés: la genialidad fue crear el A, atendiendo a las necesidades pastorales. Antes, el curso seminarístico convivía, a su modo, en el mismo currículo con el doctoral, salvo un seminario. Se diferenciaban además en la tesina para la licencia (que recién se comenzaba a exigir) y en el tipo de examen final. "Por falta de profesores se había tenido que fundir en 1963 (1964, según $I b ., 494)$, los cursos doctoral y seminarístico en uno solo” (R. Krebs, M. A. Muñoz y P. Valdivieso, Historia de la Pontificia Universidad Católica de Chile 1888-1988, Santiago 1994, ed. U. C., p. 1127).

(27) Entre inglés, francés y alemán. Me parece que el italiano fue agregado después.

(28) Creo que esta debe tener un lugar más reducido en el A. El A, además de una buena formación bíblica, debe atender sobre todo a la sistemática y a su aplicación pastoral. En el B fue genial la intuición de Juan Ochagavía, que, contra lo que se suele hacer en todas partes, juntó en un solo ramo Cristología y Trinidad.

(29) Al comienzo no había ninguna exigencia de idiomas para el A. 
simplemente menos en el A, ha desdibujado a veces las diferencias entre B y A, que entonces algunos tienden a vivenciar como curso mayor y curso menor (30). Espero que ahora, con una mayor exigencia de lenguas clásicas en el currículo $\mathrm{B}$, se marque mejor la diferencia, para provecho de todos. Respecto a fortalecer las lenguas clásicas en el B, algunos creen que es una vuelta al pasado. Pero han transcurrido más de 30 años desde nuestra opción anterior (en el momento álgido del postconcilio) y nuestros alumnos no llegan actualmente a un mínimo que les permita un más fructuoso contacto con el N. T. y con la tradición. ¿No irá a haber en esto una vuelta de péndulo en aquellos lugares en que sea realizable? Con el cambio conciliar quedó claro que las lenguas clásicas no se requieren en la formación para el ministerio (currículo A). Pero una seria formación para teólogos, como pretende ser el B, parece requerirlas (31). En el decanato de B. Villegas (1974-1976) se introdujo un año común para que los alumnos pudiesen discernir mejor entre A y B, exigiéndose un 5 de promedio para el B. ¿Han discernido mejor? (32).

Los nuevos currículos nacen en el ambiente postconciliar que insiste en el diálogo con el mundo, y no necesariamente con la filosofía, y en el que se vive una gran desmotivación respecto a lo llamado 'teórico'. Para motivar, se estudia simultáneamente filosofía y teología (la filosofía ya no es una etapa previa), disminuyéndose además la filosofía sobre todo en el A (33). Entran las ciencias humanas. Se cree también que la teología se hace mejor en diálogo con otras materias que se estudian a la vez. Así, llegar con la filosofía hecha, sería dificultar la comprensión de la mentalidad bíblica. Integrando de este modo filosofía y teología, seguíamos una vasta corriente mundial, que da la impresión de haberse esfumado actualmente. Esta integración ha resistido en los primeros años hasta el presente, lo que se espera cambiar. Los primeros en presentar problema a esta integración fueron los religiosos, que venían con la filosofía hecha (34). La formación filosófica de nuestros alumnos ha sido normalmente pobre (35); esperamos que ahora mejore (36). Vol-

(30) Algunas veces no ha sido buena la experiencia de profesores solo para el A, cuando estos eran de menor calidad académica. Por lo demás, ser solo profesor del A debería conducir a una buena experiencia de sintonía con los alumnos y el programa, y a la respectiva especialización. Bajo ciertos aspectos puede ser más difícil ser profesor del A.

(31) Confieso que, aunque no fui el autor de esta idea, mucho me gustó.

(32) De hecho en el B ha habido numerosos alumnos que buscan la mejor formación teológica para su ministerio y no les interesa prepararse para teólogos. Algunos viven quejándose de las exigencias típicas de una buena formación para esto último.

(33) Este currículo inicialmente estuvo comprimido a cuatro años. El profesor Rada llegó a proponer un plan que dividía todos los ramos dogmáticos en un aspecto bíblico histórico, otro sistemático y otro pastoral, con lo que multiplicaba por tres los ramos, y sobre eso armaba un currículo. Esto fue desechado en una tensa asamblea. Este profesor, en el decanato de B. Villegas, dejó la planta después de ser rechazada por el Consejo su apelación por no renovación de su nombramiento que expiraba.

(34) En mi segundo decanato se hizo un horario en que los que entraban al A con la filosofía ya hecha, podían hacer dos años, de los que integraban teología y filosofía, en uno. Creo que venir con filosofía hecha se debe en los Salesianos, a que les interesa tener una formación primera más compacta según el carisma de la Congregación. Los jesuitas añadieron filosofía a su formación de juniorado, decepcionados de las clases de Filosofía de nuestra Universidad, aprovechando la creación de la Universidad Alberto Hurtado.

(35) Repercutió en esto la crisis del Instituto de Filosofía y que a menudo no nos destinaban los mejores profesores.

(36) La actual reforma del currículo A prevé un fuerte aumento de créditos filosóficos. 
viendo a los currículos, creo que estamos más contentos de nuestros resultados en el B que en el A (37): nos es más fácil saber cómo formar un teólogo. Tampoco ha sido fácil encontrar buenos profesores de teología sacramental y de pastoral. La actual reforma en curso del A es más profunda que los retoques del B.

Definidos los objetivos de los dos currículos, había que implementarlos. Los tiempos de la reforma propiciaban los ramos optativos para que cada alumno configurara su propia carrera. Sucedía que, antes de que egresaran los alumnos de una promoción, ya había sido cambiado, para los nuevos, el plan de estudio (38). Hasta que en el B se asentó el plan de "Tunja" (39), que con leves retoques persiste hasta hoy (40). Había preocupación en algunos profesores por las lagunas que quedaban en ciertas materias de dogma. Para contrarrestar eso, en el decanato de B. Villegas, promulgaron el actual temario de examen del B (41). Esto obligó a los profesores a responsabilizarse por todos esos temas. Gran paso en el mejoramiento de los ramos dogmáticos fue la institución, en mi primer decanato, de los exámenes ante comisión al final de los semestres respectivos.

\section{3) EL DESAFÍO DE LA INVESTIGACIÓN}

La Facultad ha vivido bajo una fuerte sobrecarga de docencia, consagrando muy poco tiempo contratado a la investigación, si lo queremos comparar con otras unidades de la Universidad. Creo que esta situación ha tendido a mejorar en los últimos años (42). Frente a esto, mi opción personal fue servir medio tiempo en la Facultad (43), y así poder dedicar el otro medio al estudio e investigación por mi cuenta. Agradezco a la Compañía de Jesús todos los años en que me ha dado ese tiempo gratuito para esta opción. ¿Pero es esto normal en una Facultad universitaria? Creo que este es un tema que hay que seguir reflexionando y madurando, evitando, en lo posible, el contratar investigaciones mediocres. Otros profesores siguieron muy meritoriamente otros caminos ante este mismo problema. Creo que lo

(37) El A ha sufrido una serie de transformaciones. Creo que un tiempo estuvo cerrado a los laicos. Después vino la imposición que hizo la Universidad a todas las carreras, exigiendo un ciclo básico, después del cual se seguía a la licencia en esa carrera o se entraba a pedagogía. Así se pretendía mejorar la formación de los pedagogos y se ofrecía más alumnado a las diferentes disciplinas, que esperaban que los mejores alumnos continuaran en ellas. Nuestra Facultad solo destinó el A para ciclo básico. Creo que para terminar de pasar a pedagogía se les exigía el Bachillerato en ciencias religiosas. El ciclo básico desapareció posteriormente de la Universidad.

(38) A veces era pintoresco ver cómo los profesores peleaban por los créditos de sus respectivas materias.

(39) Creo que en el decanato de B. Villegas.

(40) El A se expandió a un quinto año y su tesina se reemplazó por una lectura dirigida.

(41) Primero fue para el examen de licencia y después quedó para el bachillerato, cuando en mi primer decanato, conforme a Sapientia Christiana, hubo que dividir entre el ciclo básico (5 años de filosofía y teología) y los dos años de licencia especializada. Obviamente que esta división incidió en una fuerte reducción de los optativos en el B (en el bachillerato). Para el A, en el mismo decanato, se hizo un tesario en vez de temario, que apuntale mejor la memoria para que el futuro ministro se acuerde de lo esencial.

(42) Ha ido creciendo paulatinamente el número de tiempos completos equivalentes que contrata la Facultad.

(43) Salvo los tiempos de decano y ahora al final, a consecuencia de algunos cargos como la Dirección del Postgrado. 
que ha investigado la Facultad en este período, no es tan poco ni de mala calidad. Basta con fijarse en las numerosas publicaciones. Esto se debe fundamentalmente al entusiasmo de algunos profesores que se han jugado por esto a tiempo y a destiempo. El que haya sido así (voluntario), ha incidido en la buena calidad.

Pero además de la dedicación y entusiasmo de esos profesores, de nuestras revistas y otros medios de publicación y sus círculos de lectores, han influido: equipos de investigación, como los históricos ya señalados, los seminarios "internos" de la Facultad que se programan anualmente (44), al parecer desde el decanato de B. Villegas (45); los Seminarios de Estudios Patrísticos y los Congresos de religiosidad popular, antes mencionados; otros tipos de encuentro, congresos (46), círculos de estudio; la docencia del postgrado y sus tesis de licencia y doctorado; la necesidad de hacer apuntes para los alumnos de pregrado (47); el PREI y las ayudas para publicación, intereses particulares. Relativamente pocos se han acogido a proyectos Conicyt y Dipuc, etc. (48). Gran maestra en esto ha sido A. Meis, quien además ha creado un equipo de investigadores jóvenes, que ya tiene sus publicaciones. Hemos sido apoyados por una biblioteca suficiente, a la que la Facultad, por su cuenta, desde 1990 (por señalar una fecha) le ha dado 146 millones extras para la compra de libros, cosa no vista en nuestra Universidad, y gracias a la austeridad en otros gastos. Sigamos teniendo un cuidado preferencial de nuestra Biblioteca. Entre las cosas que han ayudado a la investigación, también se destacan los períodos sabáticos.

La revista Teología y Vida cambió de cariz: de estar orientada a la reflexión teológica para el público chileno pasó a centrarse en el diálogo con nuestros pares de otras Facultades. En esto subió su nivel. Anales, de revista y anuario, se convirtió en este período en publicación de monografías, que son tal vez nuestra contribución más seria a la investigación: publicó buenas tesis doctorales (49), trabajos monográficos (50), alguna recopilación de artículos (51), homenajes (52). En resumen, el

(44) También han participado en ellos, en los últimos años, algunos profesores de la Facultad de Teología Evangélica. A la vez se ha realizado una sesión conjunta anual con los profesores de dicha Facultad sobre un tema previamente acordado.

(45) Se suelen publicar en un número doble de Teología y Vida.

(46) P. e. de Patrística, de Derecho Canónico, de diversos temas teológicos e históricos (especialmente latinoamericanos).

(47) P. e., mis propias investigaciones se han centrado en esto.

(48) Quizás sería bueno que los profesores que más investigan puedan tener un ayudante de investigación, formado por ellos y contratado por la Universidad, aunque no se presenten a concurso para esto. También convendría formar más equipos de investigación, en que sobre todo los profesores jóvenes tomen parte según sus intereses. Esto podría substituir, en cuanto participación, la fallida vida de los departamentos.

(49) Unas 15. Además, unas 4 de licencia.

(50) P. e., y no repitiendo lo que ya se dijo respecto a teología latinoamericana y estudios históricos, J. Jiménez sobre los Ejercicios ignacianos, De la Taille y Louis Lallemant, J. Noemi sobre la interpretación teológica del presente, A. Meis sobre Orígenes, S. Silva sobre la técnica, M. A., Ferrando respecto a una teología del Padre en Jn, etc.

(51) B. Villegas sobre S. Pablo. Este eminente biblista lamentablemente no ha sido reemplazado hasta ahora. Entre sus numerosas y valiosas publicaciones está El Libro de los Salmos, en ediciones U.C.

(52) Estos han sido a los profesores: Julio Jiménez, A. Moreno, B. Villegas, S. Zañartu y F. Retamal. Han sido distinguidos con el Doctorado 'Scientiae et honoris causa' de nuestra Universidad J. Jiménez, J. Medina y A Moreno; y con el doctorado 'Honoris causa' B. Villegas. Han recibido el título de profesor emérito: J. Medina, F. Retamal y S. Zañartu. 
cambio de estas dos publicaciones reflejan un serio impulso hacia la investigación. Pero la promoción de una buena investigación sigue siendo el desafío de la Facultad, que puede ir entretejido con una buena escuela de postgrado. La investigación y el postgrado se refuerzan mutuamente. De la investigación dependerá la vitalidad y validez de nuestra teología.

\section{EL AMBIENTE DE FAMILIA}

Comencé mi docencia en la primitiva sede, hermoso edificio regalado por doña Isabel Brown de Brunet a la Facultad (53). Se respiraba un aire de familia. En el decanato de J. Ochagavía (1968-1970) nos trasladamos a la Casa Central ocupando el lado que colinda con Portugal del patio Carlos Casanueva. En el decanato de P. Gutiérrez (1971-1973) emigramos a Campus Oriente, donde fuimos acantonados en unos sucuchos de madera (54). Era la pobreza de Belén. Nuestra Biblioteca fue peor tratada: parte quedó bajo el zaguán de entrada, y otra parte se cubicó hasta el techo, detrás de una escalera. Actualmente, por cierto, ha mejorado su espacio, pero todavía no recuperamos la unidad, funcionando con depósitos inaccesibles a los profesores. Esto no habla muy bien del aprecio de nuestra Universidad por la cultura e investigación. Finalmente nos trasladamos al sector que ocupaba la Facultad de Derecho en mi segundo decanato (1992-1995) (55), ampliándonos actualmente a lo que era la Escuela de Historia. Y en este nuevo hábitat de la Facultad, dejando a un lado los depósitos de la Biblioteca, estamos satisfechos.

Ha sido una peregrinación previa a nuestro futuro traslado a San Joaquín, pero nunca se perdió el aire de familia. A esto también han contribuido, además de las buenas relaciones con los alumnos, los administrativos y la bibliotecarias. Recordemos, a modo de ejemplo, la figura de Raquel Urrejola (56). Con todo, hubo tensión interna en los tiempos de la Unidad Popular. Pero el decano Pedro Gutiérrez (57),

(53) El palacete Ghigliotto. Ocupada la Facultad por la toma, los profesores nos renuíamos en la casa madre de las religiosas de la Providencia. Los seminaristas que participaron en el plebiscito pidiendo el cambio de Rector (Mons. Silva Santiago), eran expulsados del Seminario, si eran sorprendidos, porque la votación la hacían diseminados en otras escuelas. Hubo declaraciones contrarias en El Mercurio entre el decano Medina y el representante de los alumnos. Los alumnos terminaron eligiendo un religioso para este cargo. En los tiempos de la toma de la UC hubo una reunión de profesores interfacultades en la parroquia de la Anunciación. Ante la objeción de algunos de que la reunión era ilegítima porque no correspondía a la estructura de Facultades de la Universidad, tuvo alguien que recordar que la libertad de reuniones estaba garantizada por la Constitución de la República.

(54) En mi segundo decanato recuperamos el acceso a un baño de profesores.

(55) Fueron difíciles las negociaciones, porque cada uno de los decanos de Campus Oriente pretendía aumentar su propio espacio y, por otra parte, la Universidad no tenía intención de gastar demasiado para el traslado: y el gasto resultó ser alrededor de los 90 millones, según me parece recordar. Gran ayuda prestó el profesor Cristián Johansson, entonces recientemente nombrado subdirector administrativo de la Facultad.

(56) De ese tiempo eran la Isabel Pérez, el auxiliar Sergio Carrasco. Nos tocaba dialogar con el vicedecano Waldo Romo y el secretario Marciano Barrios.

(57) Su elección para la terna de decano se realizó en un gimnasio de la Casa Central. Fue la única vez que intervinieron con voto ponderado los alumnos (tiempos de la Reforma). Advertí al Decano J. Ochagavía que podía ser complicado el cálculo de los votos: se trataba de una regla de tres com- 
con su bondad, su amplitud y su buen juicio, supo mantenernos dentro de los límites de una tensa familia. Y los límites eran difíciles, porque, p. e. uno de los profesores, Pablo Richard, era dirigente del cordón Cerrillos y otro académico, Percival Cowley, era el presidente del sindicato de profesores y administrativos, Spepaduc, que facilitó la Casa Central para que los mineros de El Teniente se atrincheraran en ella (58). Recuerdo que hubo una reunión de profesores, creo que en la casa de retiro de Schönstatt, en que se nos expuso el punto de vista marxista sobre la historia (59).

El golpe militar nos encontró en Campus Oriente. Y vinieron los graves conflictos de los estudiantes. En algún momento, pareció como si el Centro de Teología, dirigido, p. e. por Freddy Parra, encabezara el movimiento estudiantil del país (60). Hasta me tocó hacer la guardia ante la tablilla de los alumnos de Teología para que no fuera despedazado su contenido por los estudiantes de gobierno, a veces venidos especialmente de S. Joaquín, que desataban la violencia en el patio del quiosco. No es que yo estuviera por lo colocado en la tablilla, sino por la paz y el respeto. Otras eran las clásicas peleas de los estudiantes de Campus Oriente con los carabineros, que entraron más de una vez al recinto universitario. Bajo la presidencia del Centro de alumnos de Joaquín Silva, la mitad del estudiantado de Teología fue suspendida por firmar una carta al Rector. Coordinados por nuestro vicedecano, Waldo Romo, los profesores de la Facultad, salvo dos, organizamos un horario alternado en la parroquia Santa Bernardita para los alumnos que no podían ir a clase dentro de la Facultad. Cuando Rectoría levantó la suspensión y prolongó las clases del semestre, nosotros no hicimos ninguna, porque ya teníamos puestas las notas. En mi primer decanato, Rectoría propuso el traslado de la Facultad a la Casa Central (hasta nos prometieron un ascensor). Respondimos que no, porque no cabía Filosofía. En los decanatos de E. Escudero (1983-1988) intentaron fallidamente trasladarnos a una casa que el Ministerio de Educación destinaba para nosotros en la avenida Matucana.

En mi primer decanato vencía el plazo para hacer que los Estatutos de la Facultad (61) se conformaran a la reciente constitución Sapientia Christiana. Sobre un primer borrador de F. Retamal, revisado por B. Villegas y E. Escudero, el Consejo trabajó arduamente. Aprobados por la Facultad, fueron llevados al Consejo Superior, donde tuvieron que enfrentar una contrapropuesta presentada por Rectoría y el Pro Gran Canciller con numerosas correcciones que limitaban la debida autonomía de la Facultad. Era

puesta. Hice una mesa de cálculo con el académico Cristián Vial y un alumno. Hecho el primer escrutinio se anunció que no había ningún elegido para la terna. Manifestamos a la dirección que nuestros cálculos no concordaban con los de ellos. El decano mandó llamar al director de la Escuela de matématicas, Dr. Rolando Chuaqui para que dirimiera el problema. Impaciente espera de toda la Facultad en el gimnasio. La fórmula de Chuaqui dio el mismo resultado que la nuestra.

(58) Una vez que pasé frente al Hospital, me pareció ver una ametralladora custodiando una posible entrada al complejo de edificios.

(59) Habló Fernando Castillo Lagarrigue, sobre Fe e Historia (véase Teología y Vida XIII (1972) 124-126).

(60) Me contaron que frente a una protesta que iba a ocurrir, el gobierno había decidido llamar a conscripción militar en el regimiento Buin a los rebeldes de Teología. La Providencia quiso que la protesta se suspendiera en el último momento.

(61) "La S. Congregación para la Educación Católica en carta dirigida al Pro Gran Canciller declara que el decreto del 16 de julio de 1938 de dicha Congregación constituyó a la Facultad de Teología como persona jurídica 'a se stante' ante el Derecho Canónico y que, por lo tanto, la Facultad no tiene la misma y única personería jurídica canónica y civil que la Pontificia Universidad Católica de Chile" (tomado de la Cuenta del Decano del año 1981). 
difícil afrontar el Consejo, siendo el decano de Teología el único decano elegido en Chile, por tanto no nombrado por la confianza de las autoridades. Defendí lo nuestro en el Consejo, ganando casi todas las votaciones contra las excesivas intromisiones de Gran Cancillería; después apelamos al Pro Gran Canciller contra las intromisiones excesivas de Rectoría. En total habíamos perdido cuatro puntos importantes, que fueron apelados a la Sagrada Congregación, quien nos dio la razón. Así nacieron los actuales Estatutos que nos rigen. Entonces hubo que armar el currículo de Licencia especializada, el postgrado. Dadas nuestras pocas fuerzas y siguiendo la intuición de Sapientia Christiana, se lo estructuró con mucha flexibilidad tutorial (62), dando gran importancia a la tesis y reduciéndonos, por mientras, a la mención en Teología dogmática (63). Debería ser más normal que los bachilleres en teología prosiguieran su estudio en el postgrado.

Fue humanamente dura la exigencia de doctorado, primero para profesores adjuntos (64), y después para auxiliares, que impuso la Sagrada Congregación en la aprobación de los Estatutos (65). Tenemos la impresión de que la Facultad contó con gran apoyo de la Universidad en los Rectorados de Fernando Castillo y según parece en el actual. En los rectorados intermedios, en cambio, nos parecía percibir más bien una gran desconfianza hacia nosotros.

Notable ha sido la incorporación de profesores laicos, que ha sido coronada al tener un laico como decano (profesor J. Noemi, 2001-2003), y el aporte femenino de la profesora A. Meis, interesada también en los aspectos de espiritualidad, mística, belleza, etc. Llaman la atención las variaciones de las opiniones de los alumnos respecto a algunos profesores, no habiendo ellos cambiado mucho. Volviendo al ambiente de familia, es una gran gracia de Dios el que la Facultad nunca se haya polarizado en dos bandos en las elecciones de decano. Las sucesiones han sido en paz y conforme a los reglamentos. Quizás por la escasez de candidatos, la Facultad ha sido más bien conservadora. Así tenemos dos decanatos seguidos de Escudero y Silva, y dos discontinuos míos. De la terna elegida a fines de 1991, los tres, por su orden, han sido decanos. La convivencia entre los profesores ha sido bastante buena, superada la tensión del tiempo de la unidad popular (66). A este buen ambiente de familia se han sumado, en los últimos años, las reuniones anuales con los profesores del Seminario Pontificio, y un grato ambiente ecuménico y de diálogos interreligiosos.

En el decanato de B. Villegas, los seminaristas de Santiago dejaron de asistir a la Facultad (67), y posteriormente lo harán los de Rancagua. Los seminaristas ha-

(62) Un currículo así requiere de su Director un constante cuidado para que lo tutorial se emplee bien y se exijan los idiomas correspondientes. Es importante también que los seminarios enseñen el método de trabajo de tesis y el respectivo uso de la biblioteca.

(63) Se confeccionaron también los primeros temarios prototípicos para el examen de grado.

(64) Fueron derogados los nombramientos hechos por el Cardenal Raúl Silva considerando dos licencias como equivalentes.

(65) Solo terminaron siendo exceptuados, por la misma Congregación, el profesor auxiliar Waldo Romo y los adjuntos Gabriel Guarda y Eliseo Escudero.

(66) En una de las reuniones de profesores, Ronaldo Muñoz al ser increpado como 'profeta', respondió llamando 'escriba' a su interpelante. Años después, hubo una asamblea en que perdió la posición del decano M. A. Ferrando, que aceptaba integrar nuestra biblioteca en una futura biblioteca que se construiría en Campus Oriente

(67) El Cardenal Silva invitó a su casa a un grupo de profesores para que, como él nos dijo, le perdonáramos este pecado; pero no pretendía volver atrás. En otra ocasión le preguntamos qué quería de nosotros, y respondió: títulos. 
bían sido alumnos fundadores de la Facultad. Actualmente están afiliados a ella, igual que recientemente el Seminario de San José de la Mariquina. Al comienzo, la separación del Seminario Pontificio produjo recargo docente para nuestros profesores, varios de los cuales comenzaron a enseñar también en el Seminario. Pero a la larga, la Arquidiócesis se ha visto más obligada a formar profesores para el Seminario, que terminan a su vez colaborando con nosotros. Con todo, sería deseable, para tener un clero más cultivado universitariamente y para mayor unidad de los futuros ministros en Santiago, el retorno, p. e. del último curso de estudios, a la Facultad. Este movimiento disgregador de centros de estudios es contrario al unificador que se produjo al terminar el Concilio. En mi primer decanato, los redentoristas fundaron un Studium aparte, con el que casi no hemos tenido relación. En cierto sentido es bueno para la Facultad que existan diversas ofertas de estudio, para no cargar con la responsabilidad de ser el único centro teológico para los futuros sacerdotes, donde habría que formarlos aunque los candidatos, por capacidad o interés, no estuvieren a nivel universitario (68).

\section{5) EL SERVICIO A LA UNIVERSIDAD Y LA PLANTA ASOCIADA}

Con la Reforma se rompía la antigua estructura de las Facultades en cuanto estas contrataban, por su cuenta, todo lo que necesitaban. En un espíritu de trabajo interuniversitario, cada escuela debía dar, en su especialidad, los respectivos servicios a las otras. Así, Teología debía heredar las clases de cultura católica que antes se impartían en la Universidad con poca llegada. A la oferta del Vicerrector Académico Fiori, respondimos, en primera instancia, que no, porque éramos muy pocos y eso nos descentraría (69). Pero en 1974 tomamos directamente los cursos de extensión admitiendo a algunos de los profesor del DETU (70). La Universidad programó estos cursos como uno de los cinco de formación general que todo alumno debía tomar. Dentro de esas categorías los alumnos optan por uno de la diversidad de cursos que la Facultad ofrece. Hasta más de 2.000 alumnos por semestre, algunos de los últimos años, han pasado por ellos o por cursos de servicio para sus unidades. Esto ha sido un éxito en cuanto la buena aceptación que han tenido, aunque son considerados poco exigentes. Siempre habrá un dilema entre ofrecer la cultura y exigir, u ofrecer la fe y esperar la respuesta libre. Pero esta falta de exigencia coincide con que también los alumnos de la Facultad piensan que nuestros cursos no exigen lo debido, aunque algunos profesores compensemos con una mayor exigencia. Solemos poner notas generosas. Es un problema para reflexionar.

Para hacer los cursos de extensión (y uno que otro a alumnos propios) necesitamos contratar otros docentes, los que no pertenecen a la planta de la Facultad, sino que fueron catalogados como asociados. Su nombramiento suele ser anual. Así he-

(68) Al respecto pueden verse las dificultades que hubo para llevar a cabo la fundación de la Facultad en J. Jiménez, Apuntes para la historia de nuestra Facultad de Teología, pp. 225-228 (Teología y Vida XVI (1975) 221-240.309-345). Cf. las reflexiones del P. Hurtado en carta a Mons. Juan Subercaseaux, en M. Barrios, La Facultad, 202-205), y Krebs..., op. cit., 373.

(69) Véase, a este propósito, Krebs..., op. cit., 38s. 
mos estado solucionando el problema que el desafío de los alumnos de la Universidad nos planteó, sin alterar por ello la planta de profesores para nuestros alumnos propios y para la dirección de la Facultad. La relación entre ambos grupos de académicos se ha hecho más fluida, en cuanto normalmente son todos invitados a las actividades de la Facultad, salvo para votar. Han variado mucho estos docentes de formación general. Se desearía un equipo más estable, más reducido y con mayor carga académica. Esto es difícil de obtener, porque esos docentes no tienen una verdadera carrera académica por delante. Hay que destacar los cursos ofrecidos por la Vice Gran Cancillería para profesores de la Universidad y el gran éxito de Teología para Laicos (71). Ambos suelen ser hechos por profesores de la planta. Los cursos para profesores de la Universidad debería ser la labor de diálogo y extensión más importante que realice la Facultad. Pero solo encontraron eco en un grupo muy reducido de profesores de la Universidad. Creo que la Facultad no se ha preocupado mucho de la pedagogía en religión. La vida de la Universidad y sus Escuelas han requerido otros múltiples servicios de la Facultad. Hemos respondido a ello en cuanto hemos podido. Somos demasiado pocos para tarea tan grande, y la extensión de la tarea puede perjudicar la seriedad y profundidad de nuestro trabajo teológico. Estas son las complicaciones que nos ha traído nuestra inserción más plena en la Universidad a partir de 1968. Creo que nuestra muy medida respuesta a las necesidades de la Universidad es una de nuestras deficiencias mayores, aunque no la más importante para nuestra Facultad. Como ya anoté, gran desafío ha sido, es y será, mejorar nuestra investigación en cantidad, cuidando su calidad.

\section{6) PALABRAS FINALES}

Represento una generación que ya ha comenzado a retirarse, que con gusto consagró su vida a la Facultad y que con esfuerzo y tenacidad hizo lo que más pudo por mejorarla. ¿En qué medida lo consiguió? La historia juzgará. Entregamos nuestra herencia a generaciones más jóvenes. El traspaso siempre es delicado. Si las generaciones jóvenes no se dedican con constancia y tiempo a la investigación seria, renunciando a muchas atracciones de la pastoral o de una vida cultural más liviana, la Facultad necesariamente decaerá. Cada generación hace su Facultad y esta va a ser siempre una tarea inconclusa. Con todo, es hermoso considerar la fragilidad de las obras humanas y, sin embargo, todo el bien que hacen, por Providencia de Dios. Los hombres, con la edad, tienden a instalarse y acomodarse, a reposarse después del esfuerzo. Igualmente las instituciones, por así decirlo, tienden a decaer (72). Se requiere el esfuerzo renovado y constante de todos por la excelencia y la verdad

(70) El DETU había reemplazado entre tanto al Instituto Superior de Cultura Católica.

(71) A este curso, dirigido durante largos años por A. Moreno, quien lo reestructuró para en tres años y medio dar una formación completa, acuden con entusiasmo muchos agentes pastorales y laicos que quieren cultivarse. En los decanatos de S. Silva (1995-2000) fue prolongado con un diploma en Teología Espiritual.

(72) También la masa de los alumnos, a menudo, tiende a negociar menores exigencias académicas. Algunos exámenes de grado se han asemejado a un catecismo un poco más extenso. 
(73), el empeño de nuevas generaciones que tiendan a lo mejor. Ser profesor es duro. Fácilmente son solitarios en un mundo socioeclesial que los rodea y no los comprende (74). Viven sometidos a la crítica de los alumnos (75); su labor académica es mirada con ojos exigentes por sus colegas y por la Facultad. Por eso, todo lo que se haga para integrar grupos de investigación e intercambio que estimulen a los profesores, todo lo que se haga por hacerles gratos su trabajo y vida en la Facultad, siempre será bienvenido.

Mucho depende de los profesores que componen la planta, que son los que eligen las autoridades unipersonales y colegiadas que gobiernan la Facultad. Grande es la responsabilidad de los decanos, que son los únicos, que, por Estatutos, pueden proponer formalmente el nombramiento de nuevos profesores. No basta con que estos tengan el título de doctor. Es conveniente leer previamente sus tesis, como se ha solido hacer, para evitar sorpresas. Igualmente no precipitarse en las promociones de profesores, por más escasos que estemos de ellos. Cada vez son más los que vienen con doctorados (76), pero hay que seleccionar los mejores para que lleguen a ser profesores de primera clase, como soñaba el P. Hurtado en sus gestiones. Hemos de contar con que vamos a estar con cierta frecuencia perdiendo parte de nuestros mejores profesores, al ser estos llamados a nuevos cargos de Iglesia (77).

Desearía que muchos alumnos no vinieran simplemente a sacar cursos y aprender de memoria para pasar exámenes (78), sino a reflexionar y pensar y formarse en el diálogo con los maestros. Es verdad que tienen sus años, costándoles volver a ir a clase y ser alumnos. Pero es muy importante una buena formación para su ministerio y trabajo futuro en un mundo cambiante. Y por todas partes, como exigencia del mundo y cultura actuales, se prolongan los estudios más allá del pregrado y de la etapa de la primera juventud. Sepan que para ser buen maestro hay que haber sido buen discípulo; que no bastan las lecturas, sino que es necesaria la socialización del conocimiento que produce la clase y el diálogo con el profesor. Da a veces la impresión que desperdician mucha oportunidad de buen saber. En parte influye en esto, el que el joven actual tiene por mejor lo más nuevo (el último computador) y lo que él puede ensayar (79); lo antiguo tendría poco que enseñarle. Y en teología choca con una revelación que viene de Dios mediante una tradición, y tiene que aprender a amarla (rumiarla dicen otros) y recibirla con creatividad en la fe. A esto

(73) Hay que revisar constantemente la marcha, porque esta con el tiempo tiende a desfigurarse y desvirtuarse.

(74) Salvo excepciones, una Facultad y sus teólogos dependen en parte del ambiente que los rodea, y en que se proyectan. En este caso, nosotros mismos tenemos que construir en Chile un ambiente que nos exija y obligue a ser una buena Facultad.

(75) Sería enriquecedor, para mejorar la docencia, un mayor intercambio entre los profesores sobre la forma de enseñar, con apoyo de algún especialista en la materia.

(76) Hemos tenido gran dificultad en encontrar nuevos profesores para Biblia y moral.

(77) Así, entre otros, se fustraron E. Viganó, J. Ochagavía, A. Moreno. A B. Villegas logramos recuperarlo.

(78) Cuando entré a la Facultad ningún alumno copiaba en las pruebas. Era un asunto de honor y de conciencia moral. El profesor dictaba las preguntas al comienzo de la prueba y volvía al final a recogerlas. Ahora se extendió la copia, defecto de la cultura escolar actual, tan indesterrable como la influencia de los comerciales o del mercado.

(79) Por lo demás, ¿estamos pasando de la cultura del libro a la cultura del saber hacer click? 
se añade que muchos alumnos viven centrados en su comunidad religiosa y en la pastoral que realizan profesionalmente; no viven la vida de la Universidad con su riqueza plural. A lo anterior se agrega una impaciencia por actuar, que los lleva a buscar circuitos cortos para la pastoral, en vez de trabajo profundo que pueda fecundar muchos años de su vida futura con una palabra válida. Y los alumnos son también importantes para la investigación, porque en diálogo con ellos los profesores investigan y atisban el futuro.

Para terminar, esta es la herencia y desafío que entregamos a las nuevas generaciones de profesores. Nuestra Facultad, que corona la teología en Chile, siempre ha sido un esfuerzo común de toda la Iglesia, especialmente de la arquidiócesis de Santiago y de algunas congregaciones religiosas. Que el Beato Alberto Hurtado, que participó en los orígenes de esta Facultad y que la quiso excelente, la proteja y le alcance las bendiciones de Dios. De mi parte gracias a Dios por haberme permitido trabajar aquí y gracias a todos Uds. 